\title{
PAR.ADIGM, SCIENCE AND SOCIETY
}

\section{INTRODUCTION*}

The subject of my contribution to the Taljaard Festschrift is focused on a cardinal aspect of the contemporary discussion in the area of theory of science, namely the relationship between science and society ${ }^{1}$, and in this connection especially the role ascribed by certain scholars to paradigms in the practice of science. Because of its bridge function, the first task will be a global getting acquainted with some characteristic accents in contemporary theory of science. If this is successfull, it can hopefully open up avenues for a view of the relationship of the remaining two components of the above mentioned subject.

\section{SOME CONTEMPORARY ACCENTS IN THEORY OF SCIENCE}

2.1. As is well known, Rationalism from Descartes to Hegel has placed the a priori structures of knowledge in the forefront. A unique paradigm of Rationalistic faith is for example Kant's conviction that he can demonstrate the possibility of synthetic judgements a priori. In the Introduction of the Critique of Pure Reason Kant formulates this as follows: "Upon such synthetic, that is, ampliative principles, all our a priori speculative knowledge must ultimately rest; analytic judgments are very important, and indeed necessary, but only for obtaining that clearness in the concepts which is requisite for such a sure and wide synthesis as will lead to a genuinely new addition to all previous knowledge" ${ }^{\text {"2 }}$.

It seems to speak for itself and to pose no special problems. Yet, it contains one of the most difficult nuclear problems of modern times, namely the problem of providing a rational for progress in human culture and science, and specifically the relationship between the structural given and the empirically discoverable new data. In the thesis quoted above, Kant sees nothing less than the main task of our pure understanding, which in the exercise of its critical function can lead to science, whereby transcendental philosophy as the idea of science is the system of all principles of the pure understanding ${ }^{3}$. 
Kant is concerned about more than the analytical clarity of concept, as in the case of Descartes. He aims for a cri tique of the understanding which (1) discovers the necessary presuppositions of knowledge, (2) throws transcendental light on the a priori possibility of the way of knowing knowables, and (3) in a truly critical manner discovers the foundations for scientific points of departure (principles), and is not merely satisfied with a dogmatic usage ${ }^{4}$.

At least four aspects from the Kantian heritage are important for the understanding of priorities in contemporary theory of science, namely (1) the relationship between idea and reality and the founding and demarcation of science, respectively "model" science, (2) the creative view of rationality, (3) the role of an a priori frame of reference and the problem of presuppositions, and (4) the critical possibilities of a system. Individual accents which within the general content of rationalistic faith receive various forms in the work of Hegel, Fichte and others, each have their own charm, but do not touch on the core of the actual paradigm and for the sake of limitations of space they need not be discussed here ${ }^{5}$. However, it would be clarifying to mention a few developmental moments of continuity and reaction.

2.2.1. According to Karl Marx the time for a static interpretation of reality is passed. The task of philosophy is to change reality dynamically ${ }^{8}$. The problem is not one of possessing and adding to our knowledge, but one of determining how one can use one's critical insight into the patterns of society to change the machinery of the various social forms?.

The critically constructive implication of Kant's Rationalistic system are thus specified and concretized in terms of the factually given, existing, historically determined forms of society. This explains the increasing accent on negative dialectics within especially twentieth century neo-Marxist tendencies, as for example in the acute writings of $\mathrm{T} W$ Adorno ${ }^{8}$. The creative constructive moment only plays its role behind the screens of a mere chance of luck, as finally acknowledged by $H$ Marcuse. The dogmatically assured faith in progress which was loaded with technocratic power, is thus subjected to a critical devaluation. 
The just presented philosophical idea of practical change also contains the roots of the contemporary fashions in philosophy, such as praxeological philosophy, with genetic situational characteristics (the changing of structures), relevant science (engagé), and the democratization of structures of society, especially the university. The message is clear: in so far as Kant and perhaps all of the early modern times as such, are still important for today, this must be restricted to the critical Kant of the Critique of Practical Reason. But the critique, of course, is especially appropriated then for twentieth century purposes and even for futurological purposes, in which case the Rationalistic doctrine of principles no longer really needs to be treated.

In the second place, the following relationships in the Theory of science become increasingly problematic: the relationship between the logical a priori and empirical factuality, between formal and situationally determined systems (including natural language), between physics as the model natural science and sociology as the model human science, between exactly determinable descriptive and statistically approximating probability theories.

In several respects this implied a change of accent from science as a result with its presuppositions, to the historical, anthropological, methodological and social aspects of science.

2.2.2 A second important change of focus concerns the struggles of especially W Dilthey, not to succumb to the emptiness of historical relativism. In various ways, various twentieth century scholars such as J Dewey, $M$ Foucault, J Habermas and $\mathrm{J} H$ van den Berg show us the consequences of his innovative analysis ${ }^{9}$. In this respect we find that today views about the historicity of (even scientific) ideas find broad acceptance, internally connected to similar ideas about the changing character of human nature. From the basic and fundamental changes in nature and society, one can accordingly fathom the basic characteristics and possibilities of science. Fascinating examples of this have been given by various scholars such as $M$ Foucault, L Kolakowski, H G Gadamer and P Ricoeur ${ }^{10}$.

Science thus does not only show characteristic signs of its times, is not merely time related, but is in its own inner nature a temporal phenomenon, which can only be under- 
stood from the historical determination of the social context within which it plays its role. An adaptation of the temporal character of science is thus connected to the importance of science as the academic cultural labour of a community of thinkers, which has specific consequences for the society within which this community functions, It is understandable that in connection with the scientific domination of human society and with the situationistically hollowed out concept of reason, probability theory becomes a touchy touch stone for the scientific enterprise.

2.2.3 In the third place, it is remarkable that Husserl even though in his contribution to Logos of 1910 he still defended philosophy as rigourous science (be it the most problematic scientific discipline) - finds the key to philosophy in critical reflection and methodological research ${ }^{11}$. In line with this the essence of twentieth century science is increasingly focused on the dynamics of research. This was underscored at an early stage already, and in a more marked way than in Husserl's case, by $\mathbf{M}$ Heidegger, who illustrates this process by his method of tracing a network of tracks in the woods ${ }^{12}$. The nature of science, already concentrated in methodology in a fargoing way, thus still finds a supportive relationship to the hermeneutic paradigm, flanked here and there by dialectical decorations. But the writing was already on the wall, and the development of operational techniques as the methodical nucleus of a wide range of sciences, makes the message unmistakably clear. It should not surprise us that a meta-model could develop so fast and in such a short time. Thus, in line with the accent on critical reflection about the methodology of scientific research, there is still the possibility of a last stronghold against a radical technification of science. And so long as there is still the transcending distantiation of metascience, of metatheory and of metalanguage with respect to its subject matter, the door is still slightly open for a higher trumpcard: a synthesis of the twentieth century duo of, on the one side theory of science and on the other side the empirical state of affairs in science as it is actually given today ${ }^{13}$.

Globaly speaking, the temporarily limited character of science and its methodological problematics are accentuated, closely related to a stronger interest in theory of science or philosophy of science, and philosophical 
logic. Important contributions to this have been made by a o Black, Braithwaite, Harré, Popper and Price ${ }^{14}$.

2.2.4 In the fourth place, especially anthropological factors of science come to the fore in the twentieth century, first in Europe, especially in Germany and France, particularly through the contributions of the Philosophy of Life, of Existentialism, and also of Existentialistically oriented phenomenology. But in the last decade specifically also in North America ${ }^{15}$ (especially now that the analytic traditions are increasingly being accounted for in Europe ${ }^{18}$ ), probably as compensation for its own strongly analytical and related tendencies in the past, and perhaps also by way of giving in to a slowly increasing dissatisfaction with logical positivism, which always was and still is strong there. In this way not only a new idea of man entered into science, but the road was also opened for a new view of and application of thinking, meaning and rationality, with consequences especially for the formation of scientific theory and terminology.

2.3.1 The model for science now roughly looks as follows: Science is essentially a communal research process within a specifically determined social-historical science tradition, with as its central problem the foundation of publically sanctioned ${ }^{17}$ logical meaning and as its main task the development of techniques that are methodical-operational rules with practical relevance and implications.

2.3.2 Thus, there exists a close inner relationship between science and society. The social relatedness of the scientist as researcher, the role and channels of communication of information, the manner and effect of making givens, discoveries and insight public, and many other facets of these relationships have been researched in an intriguing manner in what is called the sociology of science by people such as $M$ Scheler, $K$ Mannheim and others. We find this uniquely represented especially in the work of K R Merton and J Ben-David, who also developed new sociological techniques ${ }^{18}$. The important role played by the research project in this respect has been uniquely demonstrated by I Lakatos ${ }^{10}$.

Within the above framework we find brilliant critiques of scientistic onesidedness by, e g, Apel, Habermas, 
Schul $\mathrm{z}^{20}$ and others, as well as helpfull analyses of certain epistemological facets of science and society $b_{y}$, among others, Hanson (foundations and significance of scientific discovery) ${ }^{21}$, Foucault (the social-intellectual backgrounds of the scientist's attitude) ${ }^{22}$ and Polanyi (whose original analysis of the so called tacit dimension especially drew a lot of attention) ${ }^{23}$.

Through contributions like that, many facets of the scientific enterprise are re-arranged and re-connected in new and clarifying ways. Kuhn's contribution - through his concept of the paradigm - to a deeper understanding of crucial matters in the theory of science discussions and research, vindicates his approach as sufficiently important to take a closer look and to critically analyse its main lines ${ }^{24}$.

\section{THE SCIENCE IDEA OF T S KUHN}

3.1. Before coming to a sketch of the main dimensions of his theory of science, we first have to pay attention to some facets of the development of Kuhn's views, making use of a simplified model to approximate the intentions of his concept of science ${ }^{25}$.

With the publication of his The Structure of Scientific Revolution $s^{26}$ Kuhn received acknowledgement in many quarters and started an important discussion in the area of the theory and history of science. This publication already means a definite stage in the development of his academic training and interest, as well as in the development of his scientific views. Later studies show further growth and at least changes of accent.

Personal experience, of course, is not always determinitive as far $\lambda$ s the nature and quality of a scientific discipline are concerned. However, in the case of Kuhn various dimensions of his own development became motives with rich consequences for his later work. Thus, an understanding and evaluation of his theory of science as such can not easily be achieved without bringing these moments of development to the fore. I limit myself to four of these motives in his thinking ${ }^{25}$.

At the end of his doctoral studies in physics Kuhn had a pedagogically stimulating shock experience: the teaching of the natural sciences and the literature of which it 
made use appeared to be out of touch with the actual state of affairs in the sciences themselves. This motivates Kuhn to engage in a study of the nature and especially the history of his discipline, finally slowly broadening out to a study of the history of the natural sciences. This gives rise to an interest in the philosophical problems of the natural sciences, and in a way even in the philosophy of science as such ${ }^{27}$. This developmental background is important, because up to his latest publications, Kuhn shows a fundamental interest in the pedagogical dimension of scientific practice, especially the training of students to become responsible scholars. For during this time standard examples of scientific insight and activity, standard experiments and standard literature (texts and textbooks) have a fundamentally moulding effect on the scientist in training, in order to make him feel at home in the commonly accepted hypotheses and the various views that are held in the relevant disciplines.

This pedagogical dimension also stimulates historical interest in Kuhn. By means of research in the history of his discipline, of the natural sciences, and even of science as such, he tries to gain insight into the assumptions and preferences of scientific members of a specialty group, doing a special piece of research. In history Kuhn also finds the examples which he uses to demonstrate the character and salient aspects of contemporary science in selected facets, to start dealing with the question of scientific progress and to critically test scientific traditions, eventually replacing them with his own approach. Historical research thus becomes a part of Kuhn's methodology of science and this explains why he is more interested in the dynamic process of the growth of science than in its products. It also explains the basis on which Kuhn, in selecting and applying historical examples, could show his own very interesting view of the problems and possibilities inherent in a history of ideas, specifically of the rise, formulation and effect of scientific ideas throughout the centuries ${ }^{28}$. This also reveals the roots of his theory about scientific revolutions; and a bit of the reason for the objections of relativism which has been expressed by the critiques ${ }^{29}$.

A second illuminating experience was the personal contact which Kuhn acquired with the way of working and the development of thinking within the humanities. This especially concerned problems about criteria for true science, which not only brought new philosophical basic 
problems of the theory of science within his reach, but also gave him an increasing and up to now permanent interest in the social factors of science and in connection with them the social-psychological factors. Important in this respect are the social commitments of the professional scientist to the group to which he belongs, and the values which are realized in this group and which come to light among other things in whatever such a group is prepared to give up and whatever it feels called to maintain. Especially psychological research can throw light on these values, according to Kuhn.

The special combination of a fourth dimension with the social-psychological, historical, and pedagogical factors in Kuhn's thought, lends his idea of science a colour and charm of its own and also allows us to decisively distinguish him from other eminent historians of science, especially in Europe; not merely from earlier ones such as Duhem, with whom he shows intentional relationships here and there beneath the surface, but also from contemporary ones such as E J Dijksterhuis, R Hooykaas, L W H Hull, H F Kearney and M Foucault.

This fourth basic point of interest in Kuhn's theory of science is the cognitive process. Just as in the case of Einstein, Bohr and several other creative spirits of twentieth century science, Kuhn also is intrigued by epistemological problems and perspectives. But in his case we do find a distinct focusing on two facets: (1) the relationship to theory formation and (2) problems of formalization, lingual formulation and communication. The epistemological factor stimulated Kuhn in his latest publications to outline a theory of knowledge of his own, in which he pays particular attention to the contribution of perception stimuli, instead of to the popular doctrine of sense-data, which today is increasingly being criticized $^{30}$.

My analysis of Kuhn's statements in his various writings confirms the impression that only the interrelatedness of the above mentioned four motives in his theory of science reveals the golden thread of his view of the constitutive demensions of science, as well as his intention in motivating and defending certain priorities in scientific discussions and debates. Those who neglect or misinterpret the mutual relationships of these four factors, more than once either misunderstand Kuhn himself, 
leading to caricatures and onesided critical evaluations, or land in an opportunistic favouring of one of these themes according to one's own preference without doing justice to the totality of Kuhn's views ${ }^{31}$.

3.2. Now I come to a discussion of some central moments of Kuhn's theory of science. In order to try to relate Kuhn's intentions in a just manner, I will follow him as closely as possible in his various relevant statements.

3.2.1 Kuhn's research is primarily focused on the dynamic process through which scientific knowledge is acquired and not so much on the logical structure of the products of scientific research. In this respect Kuhn is closer to the Pragmatism of Dewey than to the Logical Positivism of Carnap ${ }^{32}$. According to Kuhn science comes into existence through the activities of professional groups that are active in a specific scientific area or in a part of it. A basic problem of Kuhn is that of the values that hold in such a professional group, out of which we can begin to understand the course and the progress of science. He himself compactly states this as follows: "Whatever scientific progress may be, we must account for it by examining the nature of the scientific group, discovering what it values, what it tolerates and what it disdains"33. This kind of inquiry is the responsibility of the sociologist. More specifically, it is the responsibility of a social psychology which has to determine, not the individual differences in personality between scientists, but the behaviour, activities, certainties, assumptions, etc. of scientists as a group. The basic question they have to answer is as follows: "How will a particular constellation of beliefs, values and imperatives affect group behaviour?"34.

In order to understand why scientists prefer a certain choice or come to a certain conclusion, it is important to get to know the underlying factors which in a case like this direct the scientist and are codeterminative for his decision. In my opinion, Kuhn was right to direct our attention to a fact like the variability of evaluation in this case, in which we find differences in application of values. He also rightly directed our attention to the fact that choice with respect to a theory can not be made merely on the basis of logical grounds. Of course, this 
does not imply that such a process is therefore simply irrational. That kind of primitive Irrationalism is not Kuhn's view. But it is true that his analysis of the basis on which the choices are made, is not everywhere equally incisive ${ }^{35}$.

In any case it is clear that the training and forming of scientists to become specialists related to a specific group, will have an important effect on their common assumptions and decisions. This particular point of concentration, as it appears to me, sends Kuhn in a different direction from, for example, Radnitzky, who looks for the key to the theory of science in the direction of an anthropologically founded ethics of science ${ }^{36}$. This state of affairs safeguards Kuhn's intentions from mob psycho$\log y^{37}$. However, since the scientific group becomes the final court of appeal in Kuhn's view, and since this group has the final decision about what will be characterised as scientific, we do have to face the question whether we are not confronted here by the social rule of an elite. If the objection of subjectivism is too strong for Kuhn, we still need to ask whether certain tendencies of social subjectivization do not begin to colour his science ${ }^{38}$.

We probably find the key in Kuhn's view of two central concepts, namely those of "constellation" (of all kinds of factors, such as beliefs, values, and techniques) and of "value system". The inner relationship of these elucidates Kuhn's idea of paradigm. Before we can evaluate this, we first have to say a bit more about Kuhn's view of science in development.

3.2.2 In designing his theory of science from the developing nature of science, Kuhn joins the historiographical revolution in the study of science, which posed new kinds of questions and developed new kinds of research and which does not merely follow cumulative development lines for science. In this way, according to Kuhn, a new view of science develops ${ }^{30}$. His analysis of this shows the following directives ${ }^{40}$ :

Science is a dynamic, evolutionary process, but not simply because of progressive additions of individual discoveries, as has been thought for centuries. 
Science is developed with the help of antiquated theories. The latter are not in principle unscientific, but simply incompatible with theories that are now entertained. So, even antiquated theories remain important for the present state of affairs in science, and especially are they necessary for historical research. In the second place, not only is the chronological difference between less and more developed theories important, but also the irreversible unidirectionel progress of science, because of which contemporary theories were not possible a thousand years ago and theories of long ago do not fit in the contemporary situation. Important as well is Kuhn's insight into the mutually comparable but unbridgeable differences between theories, something like a typology of scientific theories.

Methodical directives are insufficient to dictate a unique and content-rich conclusion for many kinds of scientific questions. From this it appears that Kuhn does not subscribe to the late Rationalistic faith in method as the most important factor in science. Other and different factors, according to him, also play a role in the practice of science. An example would be that there is no neutral algorithm for theory choice.

The distinguishing factor of various schools is not methodical failure, because every school is scientific. Rather, the distinguishing factor is the fact that each school in its view of the world and in its practice of science holds a view which is incomparable. In certain respects this brings about partial communication. Sometimes a "Gestalt" switch is needed to notice the merits of another view. Neutrality in science is untenable, both in the sense of irrelevance (the role of the viewer who objectively registers facts from a distance), and in the sense of the value free immunization against theories containing interpretations and world views. There is no pure language of observation. Neutral and objective reports about givens are therefore impossible.

Tradition plays an important and essential role in the development of science. However, decisive for the understanding of the development of science is not the continuity of the tradition as that is expressed in the continuity of normal science, but the revolutionary process whereby an old theory is rejected and replaced by a new one which is irreconcilable with it. This implies a break, a leap and a reorientation. Also in this respect Kuhn is 
truly a son of the twentieth century, a critical opponent of nineteenth century late Rationalistic ideas of continuity of growth, of scientific development on the pattern of the gradual appearance of the contours of a map of the world as our knowledge of facts increases.

3.2.3 One point at which Kuhn's views of 'science in development' appears to be especially important, is in his view about ordinary and extraordinary science. It appears to me that the following are the most important dimensions ${ }^{40}$ :

Scientists are trained for an art, for experienced and competent work in ordinary, normal, prevalent science; that is, research on the trusted basis of certain scientific achievements which are acknowledged by a specific scientific community as basis for scientific practice. In this respect standard textbooks (popular since the nineteenth century) or also classical works of great scientists can play a special role.

'Normal science' or 'normal research' is practised within a developed, realised, truly scientific discipline, that is one in the case of which the change-over from a protoscience to a true science has been achieved, and where there is no longer a concentration on weak areas, on their elimination with the help of alternative theories.

When research in a certain area has matured, the discipline in question has theories and techniques which answer to the following requirements:

(1) On the basis of a field demarcation criterion we can say that a specific area of research is a potential science,"only if for a specific group of natural phenomena we find concrete predictions from the practice within this specific field.

(2) Prediction successes concerning any sub class of phenomena have to be achieved consistently (compare the difference between Ptolemaic astronomy and astrology).

(3) Prediction techniques must be rooted in a theory which serves as their foundation, which explains their limited success and which suggests manners in which improvements in precision and reach can be achieved. 
(4) Improvement in prediction techniques has to be a task with a challenge, which requires a high measure of talent and dedication.

In such a phase scientists no longer need to copy what came before. They can now dedicate their energy to the basic task of normal science, i.e., the solving of puzzles as a challenge to their ingenuity; and with respect to them:

(1) Try to expand the area of relevance and precision of existing experiments and theories.

(2) Improve the congruence between them.

(3) Try to get rid of conflicts between the various theories in use.

(4) Eliminate collisions when a single theory is used in different applications.

Scientists working in a mature scientific discipline are controlled by a strong network of group commitments of a conceptual-theoretical, instrumental and methodological nature. In short, they are controlled by the central role of a communal paradigm.

With the help of such a paradigm the scientist forces nature into the preformed and relatively unpliable box which the paradigm is. Normal science is not after new phenomena, i.e. the discovery of new phenomena: often those that do not fit in to the box, are not even noticed. And, secondly, it is not after conceptual novelties either: ordinarily scientists don't go for designing new theories, and at times they are even intolerant toward theories designed by others.

Ordinary science does require the solution of all kinds of complex instrumental, conceptual and mathematical puzzles, which are a special category of problems demanding ingenuity and ability in their solution. It also requires solutions which are (1) limited in nature by rules and (2) determinative for the steps of the solution. I think that here we have an important but not completely clear dimension of Kuhn's views. About what kind of rules is he talking here? According to Kuhn he means an established point of view, or formulated differently, a preconception. This is a commitment coming to expression in laws and theories. How this happens, is not concretely explained by Kuhn in detail, as far as I can see. 
An important point in connection with ordinary scientific activity is, further, that the problems of paradigm articulation are both theoretical and experimental (therefore also practical). With this Kuhn destroys yet another one of the sanctified glasshouses of Positivism. Theory and experiment are mutually so related that one of them cannot be handled without the other, according to Kuhn.

In summary, the literature of normal science consists of three groups of problems:

(1) The determination of significant facts.

(2) The relating of theories and facts to one another.

(3) Articulation and precision of a theory.

Within the free play range of ordinary science, the scientist is sometimes confronted with the problem that something is not quite right, that something is wrong in the sense that it deviates from the assumed practices and group commitments. When this develops in to a crisis (the arbitrary element in the paradigm assures that new theories cannot be suppressed too long), there is occasion for a scientific revolution, which through a change and adaptation to the accepted paradigm normalizes the disturbed situation and so the anomaly becomes the expected and accepted thing. This process begins with the loss of relevance of the paradigm and the looser application of the rules of ordinary research. This requires the discovery of new facts and/or the design of a new theory. This means that the scientist must learn to see nature in a new way, which is more than an additional adaptation of a theory. In reality this means a change in paradigm. A scientific revolution is at bottom a consequential change in world view.

From the above it is clear that the relation of ordinary and extraordinary science becomes critical in the role of the paradigm. We will have to briefly try to follow the course of Kuhn's thoughts regarding this central concept in his idea of science.

3.3. The paradigm puzzle in the views of Kuhn

3.3.1 Even though the concept of the paradigm is not new in philosophy, since for example after Plato Wittgenstein has accounted for it in our century, Kuhn's handling of the concept of the paradigm is not in the least tradi- 
tional and also very complicated, including a number of changes in accentuation as time goes on. Let us start with a simplified sketch of the most important aspects of Kuhn's view of the paradigm ${ }^{41}$.

Exemplary scientific achievements which are so unique, that they are able to attract an established group of scholars that have been practising competitive ways of scientific practice, but that as achievements are still sufficiently pliable to leave all sorts of problems open for solution by that group of scientists, can according to Kuhn be characterised as a paradigm.

Such a paradigm can be isolated in a generally acknowledged scientific achievement which for some time offers model problems and solutions to a group of scien tists and which especially comes to expression in selected examples that are typical for knowledge and insight in a specific area. On the other hand, it does make the scientist blind for phenomena which do not fit in this particular box, and in this way it does suppress on a certain level and for a certain time the possibility of seeing and discovering new things.

Thanks to the just described role of the paradigm there develops a coherent research tradition, which Kuhn calls normal science. The presence of a paradigm is therefore a sign of full maturity in the development of a certain scientific area.

A paradigm prepares the student for participation in a special scientific community and it moulds him in this fashion. Such a paradigm also ties scientific research to common rules and standards for scientific practice. Paradigm as a professional, perhaps even methaphysical or pseudo-methaphysical commitment, precedes and is more comprehensive than the concepts, laws, theories and points of view which are abstracted from it. Consequently, differing insights in formulating and viewing the paradigm itself may emerge occasionally.

This implies an implicit possession of mutually related theories and methodological assumptions, which make selection, evaluation and criticism possible. As such this sometimes creates the impression of a basic pattern (in the sense of) on which the scientist models his theories or other work. To put it differently, it directs research with the help of (1) models and (2) abstract rules. 
The paradigm has a cognitive and a normative function, i.e., it also has a regulative function with respect to the 'normal' practice of science.

Because of its foundational character, a paradigm always plays a circular role in a debate, that is, it justifies itself. A paradigm cannot be corrected through science and is not capable of testing, and as a result competition between paradigms cannot be resolved by proofs. Rather, this requires convincing or otherwise, as Kuhn saw later and made clear, there is only the other alternative of translating the one paradigm into the other.

Repeated failure of the normal scientific tradition to solve a problem or anomaly, gives rise to a traditionbreaking addition to normal scientific activity, which in cases of crisis leads to a scientific revolution, that is to a paradigm shift. Such a paradigm adjustment means a new "unified" total vision, resulting in a changed image of science and changed data, necessitating a redefinition of a specific scientific area. Moreover, it is basically a conversion to a new attitude and view. Actually, it is a decision based on faith and thus a decisive choice which is not neutral.

3.3.2 From the above it is clear that Kuhn uses the term paradigm in a global, totalitarian, comprehensive, basic, and principial sense, whereby all four basic motives of his thinking manifest themselves coherently. On the basis of various criticisms of the first edition of The Structure of Scientific Revolutions, and especially on the basis of the clarifying textual analysis of Masterman, Kuhn now holds a viewpoint which shows some more nuance. For the sake of clarity let us for the remainder speak about Kuhn (2) over against Kuhn (1) ${ }^{42}$. On the basis of text research Masterman has come to the conclusion that Kuhn's use of the term paradigm falls into mainly three groups, namely

(1) Metaphysical or metaparadigms,

(2) sociological paradigms and

(3) artefact paradigms or construct paradigms ${ }^{43}$.

An interesting result of her research is for example that (1) and (2) is broader, but (3) to the contrary narrower than a theory. 
The above leads Kuhn (2) to acknowledge the validity of a distinction between (1) a disciplinary matrix (the sociological paradigm according to Masterman's characterization) and (2) an exemplary or better: a problem-solving paradigm. The question is, whether the method of divide and rule really solves the problem. It is clear that Kuhn (2) still remains open for the four basic motives of his thought that we mentioned, even though he gives them a different foundation and articulation than he used to. It is remarkable, however, that the power of these motives becomes controlled and that the output has to be channelled anew. By means of a sketch I will simply indicate a number of aspects.

The social motive allows Kuhn, just as before, to put full stress on the scientific community, with its social commitments. Paradigms are held in common by members of a scientific group. The reverse of this is that having such a paradigm makes it possible that otherwise very different people can nevertheless constitute one scientific community. By way of empirical generalizations, Kuhn (2) subscribes to this criterium for science as group activity, but he rejects the idea that the criterium can have the status of definition and thus he kills in the bud the circular question which is constitutive with respect to the other case. I think that two reasons can be given for this.

One of them is that the historical motive requires that the concrete and actual growth and existence of scientific groups has to be the point of departure (and not a general logical definition which is based on a logical reconstruction that argues past historical differences and uses the presupposed model of a unifying science). In addition, it appears that the phenomenon "scientific group" cannot be easily delimited by means of a 'one-one' identification with the object of research as such. As it is this requires closer research of sub-groups and their actual scientific activity.

In this way Kuhn's intellectual struggle with the problem of science shows a noteworthy and very clarifying development. Logical Positivism has simplified the complex nature of science with the idea of a unification of science, having physicalism as its basic denominator. This rigorous idea of science surely cannot do justice to the unity and diversity of the scientific enterprise ${ }^{44}$. Kuhn has attempted to stem this tide, among other things 


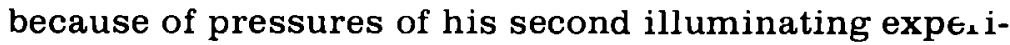
ence about the way things work in the social sciences, and thus he has socialized the scientific process in a fargoing way. Nevertheless, Kuhn himself originally did take his departure from a too simple model of science, and his continued thinking about the commitments of a scientific group as well as about the "community structure of science" as a specific criterion of science, forced him to acknowledge and honour this complexity in an increasingly strong way. He achieved this among other things by pulling the most far-going scientific specilizations within his range. The correct distinction between more and less comprehensive groups does not, however, suffice for founding disciplinary differences as such. And so the question arises whether analogous to the difference between types, sub-types and sub-sub-types, we also will need to acknowledge a family of sub-paradigms as a partial demarcation criterion. The consequences of this with respect to the decision about the nature of what is as such scientific, present the following problem: shall we have to determine basic agreements between sub-subcases in line with the specified social structure of science?

In the second place Kuhn came to see that joining a paradigm to a schoolless, basically agreeing, mature, normal science does not entirely do justice to the historic motive. For even in the so-called pre-paradigm phase the members of such a community still do show indications of a paradigm. In other words, scientific communities always and everywhere exhibit definite commitments, though not always in the same way. Therefore, the paradigm can not be used as a demarcation criterion for genuine science by reduction to the developmental facet of actual science. The consequences of this change in accent are important. For it means that the historical motive now takes its toll. At bottom this change with respect to the demarcation criterion for science shows in principle that the question "what is science?" cannot be decided with the help of the question "how does science develop?"; even though the answer to the latter does give some direction for detecting, understanding, and evaluating the basic characteristics of science and of being scientific. Here we have the important (cultural and historical) philosophical problem of the "lessons of the past". 
It also means that Kuhn(2) cannot continue to stand behind his analysis of conversion as a gestalt switch in which case convincing is the basic procedure. Rather, relativizing the difference between pre-normal, normal, and post-normal science, he is now duty bound to give a stronger accentuation to the nature and manner of symbolic translation in to another viewpoint (i e another set of commitments in peculiar and distinctive interrelatedness and coherence). An intrinsically more important role is now also assigned to the social function of symbolic communication (with the help of the lingual structure as the combining factor of a scientific community) ${ }^{45}$. This does mean that the incommensurability status becomes problematic ${ }^{46}$.

Stronger than before, Kuhn now accentuates and analyses the social lingual communication factor next to the social psychical one as the common factor of a scientific community. In order to honour the logical distinction of main and sub-groups within a scientific "family", on the basis of empirically observable givens of a variety of specialization, (presenting us with the problems of communication across group boundaries), Kuhn (2) now introduces the term disciplinary matrix. "Disciplinary" refers to the communal possession of the practitioners of a professional discipline, and "matrix" explains the orderly composition of the discipline out of various elements ${ }^{4}$.

This does not mean that the pedagogical motive is doomed to silence. According both to Kuhn (1) and (2), a scientific specialty group is held together by common elements in training and education, with responsibility for jointly serving a set of shared purposes (including the professional moulding of successors), with a largely common foundation in literature and its interpretation, and with a relatively rich basis for mutual agreement and for communication possibilities. However, Kuhn(2) joins the epistemological motive in a peculiar manner with the pedagogieal one. Apart from his view on "ostension as a pedagogic tool", Kuhn also points out that within a specific discipline the scientific group jointly, that is unanimously, and with general agreement, accepts the meaning of illuminating examples: examples which in fact initiate the young scientist into the important commitments of the group. In other words these examples are part of the central cognitive possessions of 
the group. For both Kuhn(1) and (2) it is essential that we acknowledge that such exemplars have cognitive functions which preceed the specification of criteria with respect to which they are paradigmatic or exemplary. That is, Kuhn(2) puts special value on assuring the integrity of the cognitive process as the basis for an adequate reconstruction of scientific knowledge. This implies that the empirical content of theories must be admitted from above and from below and must not be limited in a priori fashion by a formal definition. This also implies, with respect to the assimilation and storing of knowledge, the role of epistemological similarities that may not be handed over to logical rigour (of e $g$ definitions), and it implies as well the relationships between nature, stimuli, perception and theory.

The problem of epistemological similarities forces Kuhn to work out his own theory of knowledge in more detail, requiring special attention to the problem of perception, in connection with stimuli on the one hand, and theory formation on the other. Three factors play a very large role in Kuhn's theory of knowledge: the possibility of simulating stimuli through a computer (thereby rendering a technical analogy); an ontological factor in the role of a kind of adapted Aristotelian class doctrine and classification theory (once again and in a new way making the question of nature important, among others with respect to an appeal to evidence); and a pedagogical factor (the 'Johny example' gives a privileged status to the learning process and draws problems of the theory of knowledge within the lingual-symbolic framework of the learning of names for distinctions) ${ }^{48}$.

The additional material and specification Kuhn furnishes regarding details of his theory of knowledge brings us, at least from the viewpoint of the philosopher's interest, to the crown of Kuhn's science problematics. Now the highest time has come to ask ourselves what has become of the former significance of the paradigm, the so called metaphysical paradigm. The solution of this puzzle in the thinking of both Kuhn(1) and (2) produces disillusionment and offers a benevolent consolation to the philosopher specialist (with apologies to Feyerabend!).

The disillusioning aspect is that Kuhn(2) no longer considers the term paradigm suitable as such to indicate the 
common factor of a scientific community: scientific communities are indeed the "producers and validators of scientific knowledge" and seen in this way the current opinion is that in a scientific community the thing held in common specifically is a theory, and not a paradigm in the sense of "the entire constellation of beliefs, values, techniques, and so on shared by the members of a given community". In view of the fact, however, that the term theory is usually employed in a restrictive manner, Kuhn(2) now introduces the term disciplinary matrix in its stead.

The disillusioning aspect is that Kuhn(2) no longer considers the term paradigm suitable as such to indicate the common factor of a scientific community: scientific communities are indeed the "producers and validators of scientific knowledge" and seen in this way the current opinion is that in a scientific community the thing held in common specifically is a theory, and not a paradigm in the sense of "the entire constellation of beliefs, values, techniques, and so on shared by the members of a given community". In view of the fact, however, that the term theory is usually employed in a restrictive manner, Kuhn(2) now introduces the term disciplinary matrix in its stead.

The consolation is that Kuhn(2) emphasises that "a paradigm governs ... not the subject matter but rather a group of practitioners" 49 . Not only because the social factor is now given certain limitations with respect to the decision what shall properly be called a science, but also because in this way "nature" does still get priority with respect to the cardinal problem of idea and reality ${ }^{50}$. Or, at any rate, nature (or whatever term Kuhn may use for this) is at least not made completely dependent with respect to the role of intellectual commitments, as the latter play a role in the hermeneutical problem. In this way the philosopher still does receive some room to breathe. For the disciplinary matrix contains a o (1) symbolic generalizations; (2) shared commitments (the so called metaphysical paradigms) which Kuhn now concretizes as models that supply the group with analogies and metaphors, and help them to determine what can be accepted as explanation and as puzzle solution, leading to an entire spectrum from heuristic to ontological; (3) values (e g of simplicity, consistency, probability, etc) which are usually shared on a broader basis than the just mentioned two factors by 
scientists, and can be viewed as determining factors with respect to prediction and evaluation of theories; and which are also applied in individually differing ways, though still remaining important determining factors of group behaviour; and (4) (illuminative) examples ${ }^{51}$.

In especially the above mentioned (2) and (3) something remains of the global, perspectival, rather syntactical than semantical meaning of paradigm which made the views of Kuhn(1) so intriguing and which stimulated such a wide discussion. The final results of Kuhn's matured views are not merely "hum drum sociological points of information that have been known long before". However, it is only "something" that remains: just as in the case of the reactionary Ayer in former times, Kuhn(1) makes a greater impression because of the philosophical method which shows considerable power, dares to take risks, and approaches the extreme limits of a wide perspective. Even though the polemical value of a viewpoint in which Kuhn clearly stuck out his neck has been devaluated, it can nevertheless be said, I think, that Kuhn(2) comes closer to a more powerful insight into and ordering of factors of the theory of science, including basic philosophical problems ${ }^{52}$. Thus, Kuhn(2) still holds on to the possibility of viewing the world totally differently from two points of view. But he accounts for this by means of the epistemological dimension of stimuli. At this point I believe that the ontological limit of the spectrum of commitments and the role of nature with respect to stimuli, certainly needs to be worked out further and to be clarified: computer simulation of stimuli is an important experiment, but at the same time, this facet of the neural factor is the most obvious and simple analogy and not all that there are to an adequate epistemology. This also is true for the role of values in science, that is to say the normative problematics of the structure of science, which Kuhn, still bound to tradition, only hesitantly begins to treat.

Indeed, (2) and (3) mentioned above do contain some philosophical consolation, though unfortunately no more than this: not all scientists according to Kuhn are committed in this way! These components of the disciplinary matrix also contain promise of intellectual surprises when further worked out, especially if Kuhn would do a little sharpening up of his theory of knowledge. Kuhn(1) and (2) are of course not totally different persons. 
Kuhn remains faithful to himself in his basic intentions, even though the continuity of his thought from time to time brings along different and sometimes new accents, insights and intuitions. It seems that this is possible thanks to Kuhn's brilliant handling and application of the four motives of his thinking which we have mentioned above, according to the need and necessity of the moment.

4. Finally, some remarks about the significance of Kuhn's theory of science. In my opinion Kuhn correctly emphasized the more or less dogmatic, uncritical attitude of the average scientist busy with research on scientific problems or rather puzzles and their solutions. "Uncritical", not in the sense of uncritical handling of scientific tools, methods, research, discussion, etc., but in the sense of (usually unconsciously) lacking critique with respect to one's own point of departure and one's own motives (the "values" used within a certain scientific community). I believe that factually speaking and broadly speaking this is correct: 'dogmatic' undergirds 'critical'. Whether this is so as a result of certain philosophical influences which worked through specific science traditions, and what these would be, is another question, which can not now be discussed. In the above sketched view it seems then that factually Kuhn is closer to the truth than Popper, with his view of truly normal science as basically critical and always looking for instances which can falsify the results and hypotheses that are current, thus viewing the scientific community as a thoroughly open and undogmatic community. I should add, of course, that what I have just said holds just in case Popper's critical attitude is more than a merely methodological-instrumental approach. Of course, in addition to many valuable insights. Popper also in this respect does have a contribution to make, especially in so far as his view indicates the ideal which the practice of science ought to approach, namely a rigorous testing of one's own hypotheses, to see whether they can be maintained, and a continual investigation into the question as to whether the accepted results and theories are critically up to date.

However, in the final analysis this ideal is not co-extensive with the reality of scientific practice ${ }^{53}$. The apparent reason for this is important. "Normal science", that is to 
say the everyday practice of science within scientific disciplines, has developed into a specialistic treatment of the details of a certain discipline. Consequently, the critical attitude that should have begun to investigate and question philosophical bases, have been in the deep freeze for many decades. Thus, we were no longer sufficiently pliable to reflect on our own assumptions and presuppositions of accepted theories, hypotheses and axioms. Of course, not every specialist needs to strive for the ideal to become or try to be a philosopher. But it would be to his own detriment if he lost the road towards broad contextual relationships, philosophical basic questions and the central theory of science which directs and guides his thought. In the same way, a dilemma would appear if the philosopher would shrink back from detailed problem research which would ultimately, and often very soon already, land him in speculation and metaphysical dream castles. Not only what is called "Critical Theory", but also the intense interest in metascientific problems in the recent past, is proof for the fact that we face a serious problem here, but also for the fact that there is a tendency in the right direction even if it is still a bit too safe and even if some of the central problems are still passed by.

Kuhn has emphasized the need for new theories with their paradigmatic consequences, in order to do justice to the facts and to the state of affairs in a scientific area, and he has also emphasized the significance of extra-ordinary inquiries into science in response to anomalies. This is a valuable dimension of his work. But the question remains whether Kuhn's solution is sufficiently radical. Both Kuhn and Popper react to the presuppositions of Positivism, especially Logical Positivism, and they offer important new points of view. However, Kuhn's medicine is partially neutralized and made ineffective by his presently somewhat relativized division of science into dogmatically normal and critically extraordinary science ${ }^{54}$. The right perspective seems to me to be that the practice of science must actually always strive after an ideal, even though it is not always realized because our subjective behaviour and norms are not identical. But the norm does require that the scientist in the work of his research program, in looking for new facts, in solving problems and puzzles, in viewing relationships, etc., will at least try to become and remain critically conscious of his own viewpoint, of his own presuppositions 
and the implications of his theory or theories, and that he will fairly compare his own with those of others. This means that every scientist, also the philosophical specialist, will force himself from time to time to look over his own shoulder in order to gain a reflective view of his own foundations and basic motives. This need not alw ays necessarily lead to their rejection, not even to their adaptation and correction, but it will always lead to a check-up as to whether or not the safety plugs are still functioning purposively or whether they have already become antiquated or have been connected to a current that is no longer able to carry the load. Furthermore, in this way it will be easier to X-ray any cracks in the wall of preferred theories, and progress of science can continually be helped by timely remedies, which are better than letting things go until a crisis or a shock adaptation, i e a revolution, is unavoidable. The latter could easily happen simply because the necessary philosophical interest and the ability to critically test one's own views are often not thought to be inherent dimensions of the normal practice of science, as a result of an inadequate view of normativity and the factually given.

Kuhn has given us useful analyses about the community structure of science. Kuhn has also pointed out in his analyses that the ablest scientists are often members of more than one sub group. However, he has not properly seen the manner in which the activities of every sub or sub-sub group affect one another. In his theory of the structures of society, J A L Taljaard has used the Biblical image of the "bread and grain kernels" as a methodological directive ${ }^{55}$, with striking ontological implications.

Of course, an image like that has its limits of application. If used critically, it seems to me, however, that it would be a serviceable indicator of the road we have to go in our contemporary social theories and specifically in our view of the structures of society, within which our Christian scientific studies must flourish. The mixing, the quality and the processing of the grain kernels will indeed determine what the bread is going to look like as far as the subjective and inherent commitments are concerned. It is clear that the artificial walls that have been erected especially by the Positivistic tradition will have to crack up. The progress of science, even the possibility of progress, will depend on whether scientific groups 
from various disciplines amongst one another, and the scientific community (scientistically and technologically controlled as it is ${ }^{58}$ ) together with the other communities in our society, will in a truly critical but also intellectually constructive fashion accept their mutually differentiated tasks. These tasks, of course, do not only concern the control of nature, but also the deployment and its care as God's creation. And these tasks will have to be accepted, not by running away with the facts, but by attempting to understand their meaning in a normative (different from, but inclusive of descriptivel) manner ${ }^{57}$. The struggle of science theoreticians such as Kuhn (and here and there also the derailments) seem to be especially instructive for acquiring insight into the complexity of this kind of problematics ${ }^{58}$.

\section{N T VAN DER MERWE \\ POTCHEFSTROOM UNIVERSITY FOR C H E POTCHEFSTROOM}

\section{CURRICULUM VITAE}

Nicolaas Theodor van der Merwe, born 3-11-1932, Potchefstroom Address: 10, Van Graan Street, Potchefstroom, Republic of South Africa.

B.A. degree (1954), with Greek, Latin and Philosophy as majors, at the Potchefstroom University for C.H.E. Post-graduate studies in Philosophy (with H G Stoker \& J A L Taljaard) and Latin (with W N \& J J Coetzee) leading to a $\mathbf{M}$ A-degree in Philosophy (including a thesis on Philosophical Logic "Op weg na "n Christelike Logika") and a B AHonours degree in Latin. Overseas studies at the Free University of Amsterdam since 1959 in Philosophy (with H Dooyeweerd. M C Smit, D H T Vollenhoven. S U Zuidema) and Early Christian Latin Literature (with A Sizoo \& J J Thierry). Drs phil degree Oct, 1964. Also attended lectures in Philosophy at the Universities of Utrecht and Leiden (C J de Vogel, J P A Mekkes, A E Loen, C A van Peursen) and Early Christian Latin Literature at the Universities of Amsterdam and Leiden (C Mohrmann. J N Bakhuizen van den Brink \& $P$ C van der Nat). Appointed 1963 lecturer of Philosophy at the University of Potchefstroom; promoted senior lecturer 1965, professor as from 1976. 1969-1970 post-graduate research on the Philosophy of Augustine at the Free University of Amsterdam with S U Zuidema \& M C Smit as tutors.

A few publications:

"Aspekte van 'n funksionele beskouing van verbeelding en van 'n tipo. logie van teorieë oor die verbeelding". Philosophia Reformata 34, 1969. $147-178$.

"Grepe uit die kontemporêre wysbegeerte" in Die Atoomeeu in U Lig. Potchefstroom, I B C, 1969, 76-112.

"Qua via. philosophia?" in The Idea of Christian Philosophy (Festschrift D H T Vollenhoven), Philosophia Reformata 38, 1973, 84-96. 
- Sincere thanks are due to my friend Hendrik Hart for his help with the translation of the manuscript at the publication "deadline".

1 'Science here taken in a global sense, like "Wissenschaft", and not restricted to the natural sciences. 'Society' intended in a global sense as well, not excluding 'social reality'.

2 A9-10/B13-14, here quoted in the English translation of $\mathrm{N} \mathrm{K}$ Smith, Immanuel Kant's Critique of Pure Reason. London, Macmillan, 1956 (1929), 51.

3 Ibid, A11-14/B23-28 (Edition W Weischedel. Darmstadt, Wissenschaftliche Buchgesellschaft, 1956, Bd II, 61-65).

$4 \quad$ Ibid, B22 (Edition W Weischedel, 61).

5 The natural result of an exemplary focusing on the Kantian heritage - for reasons of space - is of course a reduced historical perspective, which glides over the factual historical relation between Marx and Hegel, as well as the actual development of philosophical ideas in modern times, not to mention text book dilemmas like Rationalism and Empiricism. A worthwhile correction could be comparison of perspective from the 'platform' of e g G RADNITZKY, Contemporary schools of metascience; 3rd enlarged edition, three volumes in one. Chicago, Regnery, 1973.

6 "Thesen über Feuerbach", no 11, cf especially 1,2 \& 8.

7 An interesting elucidation $\mathrm{e} g$ in the "Deutsche Ideologie".

8 Cf especially his important study Negative Dialektik. Frankfurt am Main, Suhrkamp, 1966.

9 To mention just one example, J Dewey's "Does human nature change?"' in the Rotarian Magazine, vol 52, no 2, Feb 1946, 8 sqq

10 For example M FOUCAULT in his study The Archaeology of knowledge; translated from the French by A M S Smith. London, Tavistock, 1969 and P RICOEUR, Le conflit des interpretations; essais d'hermeneutique. Paris, Editions du Seuil, 1969, or - in an even more topical setting - his "Science et idéologie", Revue philosopique de Louvain, 72 (Quatrième série, no 14), Mai 1974, 328-355.

11 "Philosophie als strenge Wissenschaft", Logos 1, 1910-11, 289-341. 12 Holzwege being a striking but by no means exclusive example.

13 A noteworthy outcome of this trend is the role accorded in certain quarters to an Ethics of science in order to involve the "normative problematics" - initially encapsulated by Logical Positivism and later on treated in a psychologistic fashion in "emotive theories" - in the discussions of science theoreticians. Cf a o, the interesting reaction of K-O APEL, Transformation der Philosophie; Bd II. Frankfurt am Main, Suhrkamp, 1973, 358 sqq.

14 For example BLACK, M, Critical thinking: An Introduction to Logic and Scientific Method; 2nd ed Englewood Cliffs, PrenticeHall, and Models and Metaphors: Studies in Language and Philosophy. Ithaca, New York, Cornell University Press, 1960; BRAITHWAITE, R B, Scientific explanation: A study of the function of Theory, Probability and Law in science. Cambridge, University Press, 1968 (1953); POPPER, K R, The Logic of scientific discovery. London, Hutchinson, $1972(1959)$ and some essays in Conjectures and Refutations; the growth of scientific knowledge. London, Routledge \& Kegan Paul. 1972 (1963); PRICE, H H, Thinking and experience. London, Hutchinson University Library, ${ }^{2} 1969$ (1953). 
15 For example, J Kockelmans.

16 For example through influence exerted by writings of W Stegmüller.

17 See the important analysis of this problematics in Dewey's thought world by H HART, Communal certainty and authorized truth; an Examination of John Dewey's Philosophy of Verifica. tion. Amsterdam, Swets \& Zeitlinger, 1966. J HABERMAS treated the social facet of attitudes towards public disclosure in an intriguing manner in his Strukturwandel der Offentlichkeit; Untersuchungen zu einer Kategorie der bürgerlichen Gesellschaf. (5 Aufl Sonderausg Neuwied) Luchterhand, 1971 (1962).

18 A basic study with a valuable comprehensive bibliography is $\mathbf{R}$ MERTON's, The Sociology of science; Theoretical and Empirical Investigations; edited and with an Introduction by $\mathrm{N}$ W Storer. Chicago \& London, University of Chicago Press, 1973.

19 An exceptionally high standard of scientific research reporting his "Falsification and the Methodology of Scientific Research Programmes" in I LAKATOS \& A MUSGRAVE (ed), Criticism and the growth of knowledge. Cambridge. University Press, 1970 91-196. (Abbreviated as CATGOK).

20 APEL, K - O, Transformation derPhilosophie; Bd II. Frankfurt am Main. Suhrkamp, 1973, 7 sqq; HABERMAS, J, Theorie und Praxis; Sozialphilosophische Studien; 3. Aufl Frankfurt am Main. Suhrkamp, 1974, especially 307 sqq; SCHULZ, W, Philosophie in der veränderten Welt. Pfullingen, Neske, 1974, 12 sqq.

21 HANSON, N R, Patterns of discovery. An inquiry into the conceptual foundations of science. Cambridge, University Press, 1958.

22 A lively gist of his approach in his television discussion with $\mathbf{N}$ Chomsky, see F ELDERS (ed), Reflexive water; the basic concerns of mankind. London, Souvenir Press, 1974, s v "Human nature Justice versus power", 133 sqq.

23 An interesting collection of essays of M POLANYI is Marjorie Grene's Kowing and being; essays by Michael Polanyi. Chicago, University of Chicago, 1969.

24 Though of course solely responsible for my own tentative ventures in this essay, I gratefully mention the intellectual stimulation of discussions with my colleague and friend $H$ G Stoker on topics related to the philosophy of science, and look forward to the publication of his research results in this area.

25 My approach accentuates a specific perspective on the significance of Kuhn's views, an approach which I do consider illuminative but which to a large extent is absent in relevant contemporary literature; I am quite aware that alternative philosophical models could possibly - and some indeed do - highlight facets subdued in my sketch.

26 1st ed 1962; 2nd ed, enlarged, 1970 (Chicago, University of Chicago Press). Furtheron abbreviated as TSOSF. Important critical essays on Kuhn's views in Criticism and the growth of knowledge (see footnote 19 above) and F SUPPE, (ed), The structure of scien tific Theories. Urbana, Chicago, London, University of Illinois Press, 1974, (abbreviated TSOST), both containing essays and replies by Kuhn as well. Important 'Book Reviews' include AGASSI in Journal of the History of Philosophy, 4, 1966, 351-4; A E MUSGRA VE in British Journal for the Philosophy of Science, 22, 1971. 287-306; I SCHEFFLER, "Vision and Revolution: A Postscript on Kuln" in Philosophy of science 39, 1972, 366-374; and 
especially D SHAPERE, "The Structure of scientific Revolutions", The Philosophical Review, 73, 1964, 383-394 \& "The Paradigm Concept"'. Science. 172, 1971, 706-709. An excellent 'micropaedic' perspective on Kuhn's position in the philosophy of science is furnished by T KISIEL \& G JOHNSON, "New philosophies of science in the USA; a selective survey", Zeitschrift für allgemeine Wissenschaftstheorie, V/1, 1974, 138-191.

27 Interesting autobiographical details in TSOSR, v sqq.

28 On this point influence of A E Lovejoy is most probable.

29 Especially D SHAPERE (see footnote 26). Like, e g, Musgrave, 294 (see footnote 26 above) and in a certain sense also J KEKES, "Fallibilism and Rationality", American Philosophical QuarterIy, 9 (4), 1972, 30-309, of especially 307, I do not consider Kuhn's supposed "Irrationalism" and "Relativism" proved (but compare footnote 32), though his rebuttal (e g TSOSR, 191 sqq and 205 sqq, as well as 'Discussion', 508, in TSOST - see footnote 26 above -, \& "Reflections on my critics" in CATGOK, 234 and 259 sqq, (cited above in footnote 19) doesn't seem to be fully to the point or detailed. To my mind Kuhn's "Subjectivism" (members of a scientific group being the sole audience and judges) as far as the theory of science is concerned, is a far pore serious issue. Lakatos' idea of criticism in CATGOK, especially 179-180, as well as scholarly discussions on the context of justification demonstrates my point from a different angle.

30 Important epistemological expositions especially in Kuhn's contribution "Second Thoughts on Paradigms" in TSOST (cited above footnote 26).

31 H V STOPES-ROE's well balanced book review in the British Journal for the philosophy of science 15, 1964-65, 158-161, e g. underscores the pedagogic factor, without, however, mentioning its connection to the other factors; the reader accordingly doesn't get an image of Kuhn's view in its totality. Kuhn himself merely juxtaposes these factors without treating their in terrelatedness as such, ef e g his "Second thoughts on Paradigms" in TSOST, 471.

32 Cf e g, Kuhn's appraisal of logic in "Logic of discovery or psychology of research?" in CATGOK (cited above footnote 26), 15. This remark is not intended to exclude affinities between the two philosophical trends, ef my "Grepe uit die kontemporêre wysbegeerte" in Die Atoomeeu in U Lig. Potchefstroom, I B C, 1969, (76112) 90 sqq. As far as Kuhn's own philosophical position in contemporary thought is concerned, it seems to me that Kuhn though more advanced - has his roots primarily in what I have termed 'Philosophy of grounded commitment' ( $p$ 97 sqq), not excluding other affinities to and reactions against contemporary trends; J Watkins' critique of Kuhn (a kind of 'construction method' - c f "Against 'normal science' " in CA TGOK, 26) should be viewed in this perspective too, it seems, as a faint echo of the (Logical) Positivistic tradition. Affinities with Lovejoy's 'history of ideas' approach is noticeable - though often concealed beneath the surface - in Kuhn's use of illustrative examples when treating the history of science - an hermeneutic factor missed by Watkins.

33 "Reflections on my Critics" in CATGOK, 238.

34 Ibid, 240.

35 M L SCHAGRIN, "On being unreasonable". Philosophy of science, March 1973, 1-8, gives a very readable digression on this 
topic. Moreover, the specific goal(s) of science are scarcely broached.

36 Quoted above footnote 5.

37 Cf, e g, Lakatos 140 \& 177 sqq as well as Kuhn 262-3 in CATGOK (footnote 19 above); the ghost of 'Subjectivism' (cf footnote 29 above) remains though!

38 Neither history nor the subjective activity of the scientist (including his constellation of beliefs, values and imperatives) seems appropriate to furnish the criteria for science as such in an ultimate sense; cf footnote 29 above.

39 TSOSR, 3 sqq

40 A digest compiled from statements especially in TSOSR, together with relevant expositions elsewhere; for reasons of space individual documentation could not be considered.

COULD NOT BE CONSIDERED.

41 Cf remark footnote 40 above. I accordingly steer clear of accentuations representative specifically of Kuhn's "modified views" in recent publications. Important studies regarding Kuhn's paradigm concept include Shapere (quoted above footnote 26) and articles by I Lakatos. M Masterman \& $\mathrm{J}$ Watkins in CATGOK (see footnote 19 above). Masterman's study is especially helpful.

42. Following Kuhn's own humorous example ("Reflections on my critics", in CATGOK, 231) but in a more serious vein.

43 MASTERMAN, Margaret, "The nature of a paradigm" in CATGOK, 65.

44 Cf, a o the following instructive studies of $H$ G Stoker: "Die eenheid van die wetenskap", Philosophia Reformata, 33, 1968, 1-31; 118-136 (Summary in English 136-148) \& "Die beginsel: eenheid en differensiasie", Koers 30, 1962, 20-45 (both reprinted in Oorsprong en rigting, I. Kaapstad, Tafelberg, 1970)

45 "Second thoughts on Paradigms" in TSOST, cf especially 473 sqq and $503 \mathrm{sqq}$.

46 Cf TSOSR, 198 sqq \& "Reflections on my critics" in CA TGOK, 266 sqq.

47 TSOSR, 182

48 Within all three factors the "empirical" zooms in to a new focus. The remarkable fact is that after Kuhn's subversive polemics with (Logical) Positivism - which even supplied his approach with the tag 'Idealism' - we now find Kuhn(2) close to an (epistemological; Empiricism, and here and there in the vicinity of some pure bred Positivists.

49 TSOSR, 180

50 Cf my exposition above, p 334, on the 'Kantian heritage'. It is important to note that this notorious issue in Idealism turns up in 20th century outfit not only with regard to the hermeneutic problem but also in the role accorded to 'model' (cf, e g. I Lakatos, "Falsification and the Methodology of scientific research programs" in CA TGOK, 135: "models simulating reality"), analogy, resemblance, etc, - 'structure' often replacing system' (in its Early Modern connotation) and 'system' becoming a technical artefact.

51 Cf TSOSR, 182-187.

52 Facets of science like, $\theta \mathrm{g}$, analogy, metaphor, lingual identification, meaning-determiners, data, the mapping and comparison of theories, "intellectual frameworks" and beliefs, scientific commitments and the internal and external relations of science, etc. 
This is an important task also confronting scientists with Christian religious commitments, a task that is just beginning to bear its first fruits in (Calvinistic) Christian scientific studies.

53 Margaret Masterman, "The nature of a paradigm" in CATGOK, 60 takes this for granted too easily, as it seems to me. Both Kuhn and Popper have underscored real characteristics of science, but onesidedly; in this respect their polemics mean a valuablecorrection of each other. Both get stuck, though, as it seems, in subjective (group) attitudes and values (Kuhn) or ideals (Popper). Lakatos, op cit, 138 (footnote 52 above) has stated correctly, I think: ". . history of science,without philosophy of science is blind"; but I may perhaps add: and philosophy of science without a normative philosophical basic idea (or hermeneutic key and, pace Lakatos, not merely a heuristic study) is blind, in any case colour-blind.

54 It may be true, generally speaking, that ". . . only when they must choose between competing theories do scientists behave like philosophers" (Kuhn, "Logic of discovery or psychology of research?" in CATGOK, 7). But I think Kuhn should look into the matter in detail why that happens usually only in times of crisis and should present us with the reasons and directing factors bearing on this fact. We here touch, so it seems, on Kuhn's blind spot as far as the Positivistic tradition is concerned: clumsiness as regards the normative problematics on the one hand, and an inadequate perspective on the history of philosophy on the other hand. I suggest that the role of competing theories is more important and also not quite what Kuhn would let us believe.

55 J A L TALJAARD, "Graankorrel en brood: Gedagtes oor 'n Skrifmatige Samelewingsleer met besondere aandag aan die Staat", Perspektief (Potchefstroom) 10 (2\&3) Sept 1971, 92-108.

56 Cf, e g, ELLUL, J, The technological Society; transi from the French by $J$ Wilkinson, with an Introd by $R K$ Merton. London, Cape, 1965; JASPERS, K,Vom Ursprung und Ziel der Geschichte. Frankfurt, Fischer, 1957, 81 sqq \& SCHULZ, W, Philosophie in der veränderten Welt. Pfullingen, Neske, 1974. 12 sqq.

57. This means inter alia getting rid of "creative reason theories" (in either Rationalistic or Irrationalistic garb) and constructing really human "active intellect theories" in stead (cf above, p 329 , (2)).

58 Instructive, e $\mathrm{g}$, Kuhn's research on the complexity of (scientific discovery, c f e g, already his "Historical Structure of Scientific Discovery", Science, 136, No 3518, June 1962, 760-764. 